\title{
Methodology to Evaluate Fatigue Damage of High-Speed Train Welded Bogie Frames Based on On-Track Dynamic Stress Test Data
}

\author{
Guangxue Yang ${ }^{1 *}$, Meng Wang ${ }^{2}$, Qiang Li ${ }^{1}$ and Ran Ding ${ }^{1}$
}

\begin{abstract}
The current method of estimating the fatigue life of railway structures is to calculating the equivalent stress amplitude based on the measured stress data. However, the random of the measured data is not considered. In this paper, a new method was established to compute the equivalent stress amplitude to evaluate the fatigue damage based on the measurable randomness, since the equivalent stress is the key parameter for assessment of structure fatigue life and load derivation. The equivalent stress amplitude of a high-speed train welded bogie frame was found to obey normal distribution under uniform operation route that verified by on-track dynamic stress data, and the proposed model is, in effect, an improved version of the mathematical model used to calculate the equivalent stress amplitude. The data of a long-term, on-track dynamic stress test program was analyzed to find that the normal distribution parameters of equivalent stress amplitude values differ across different operation route. Thus, the fatigue damage of the high-speed train welded bogie frame can be evaluated by the proposed method if the running schedule of the train is known a priori. The results also showed that the equivalent stress amplitude of the region connected to the power system is more random than in other regions of the bogie frame.
\end{abstract}

Keywords: Fatigue damage evaluation, Equivalent stress amplitude, On-track dynamic stress test, Welded bogie frame of high-speed train

\section{Introduction}

Safety is the most important property of a passenger railway vehicle. The fatigue strength of a vehicle loading structure has a substantial impact on its safety, and thus must be comprehensively assured. A series of fatigue strength analysis methods for welded railway vehicle structures have been introduced to date [1], including fatigue assessment for constant amplitude loading by the endurance limit, evaluation of fatigue test programs by cumulative damage, and evaluation of simulated multiple body systems by cumulative damage. These methods are commonly applied in the railway industry [2-6].

Han et al. [7] introduced a static load test method and evaluated experimentally the static strength for the bogie

\footnotetext{
*Correspondence: gxyang@bjtu.edu.cn

${ }^{1}$ Engineering Research Center of Structure Reliability and Operation Measurement Technology of Rail Guided Vehicles, Ministry of Education, Beijing Jiaotong University, Beijing 100044, China

Full list of author information is available at the end of the article
}

frame of an urban maglev train. Linhart et al. [8] carried out high-cycle fatigue tests with an evaluation of fatigue limit on large model components of bars with press fitted hubs made of three railway axle steels. Wu et al. [9] proposed a new crack closure based fatigue crack growth rate model in terms of low cycle fatigue behavior and improved threshold stress intensity factor range at different loading ratios. The predicted results were in good agreement with the experimental data of the railway axle used steels. Bertini et al. [10] investigated the fatigue resistance of a typical welded joint employed in railway bogie manufacturing. Zhou et al. [11] carried out stress tests of high-speed train axles along the rebuilt railway line and Jingjin intercity railway line. The $\mathrm{S}-\mathrm{N}$ curve parameters with different notches and the corresponding fatigue limits were calculated. Milovanović et al. [12] studied a methodology used to identify causes of cracking nearby the welded joint on the underframe of wagon type Sgmns for the transportation of containers and swap 
bodies. As part of the Euraxles project, a series of fullscale axles fatigue tests were carried out [13]. The fatigue limits and the stress concentration factors were verified. However, most published research are not determined based on actual, on-track test programs of the structure in question.

The speed and efficiency of train travel has been continually modernized over recent decades, so the real load situation of vehicles may differ substantially from the standard. Furthermore, the vehicle structures may crack unexpectedly during the service period [14]. The load situation of railway vehicles have been researched recently. By use of a reliable test technology, Ren et al. [15] tested the axle spring forces of the high speed EMU on the Beijing-Tianjin railway line. Zhu et al. [16] carried out theoretical research and experimental validation to investigate load spectra of high-speed trains bogie frames. Wu et al. [17] investigated the post-derailment dynamic behavior of the half car and verified the proposed postderailment dynamic model.

The bogie frame is one of the most important parts of the railway vehicle [18-22]. It plays a significant role in controlling wheel sets on the railway, and it carries the brakes, motors, gear boxes, and suspensions while sustaining the static weight of the car body. To this effect, the load conditions of the bogie frame are highly complex and accurately assessing its fatigue strength is very challenging. Numerous welded structures of railway vehicles are safety critical $[23,24]$. The dynamic stress on-track test, one of the most feasible and effective approaches to obtaining fatigue stress cycles [25], was utilized in this study on a long-term China high-speed train program to explore the dynamic stress response of the bogie frame. The results were used to build a new method for evaluating the on-track fatigue damage of the bogie frame.

\section{Dynamic Stress Test Program}

Figure 1 shows the dynamic stress test point distribution of the China high-speed train bogie frame. The strain gauge is disposed at the junction of the weld metal and the base metal, as shown in Figure 2. The tested vehicle was still in service on several railway lines including Beijing West-Guangzhou South, Beijing West-TaiyuanGuangzhou South, and others throughout the duration of the dynamic stress test program.

The bogie frame was subjected to a combined, multilevel stress during train operation. To facilitate followup analysis, the multi-level stress was transformed into equivalent constant amplitude stress based on the fatigue damage consistency law. In other words, equivalent stress is the most important parameter for fatigue.

According to the rules of the rain flow count method, the stress spectrum must first be obtained from the test data

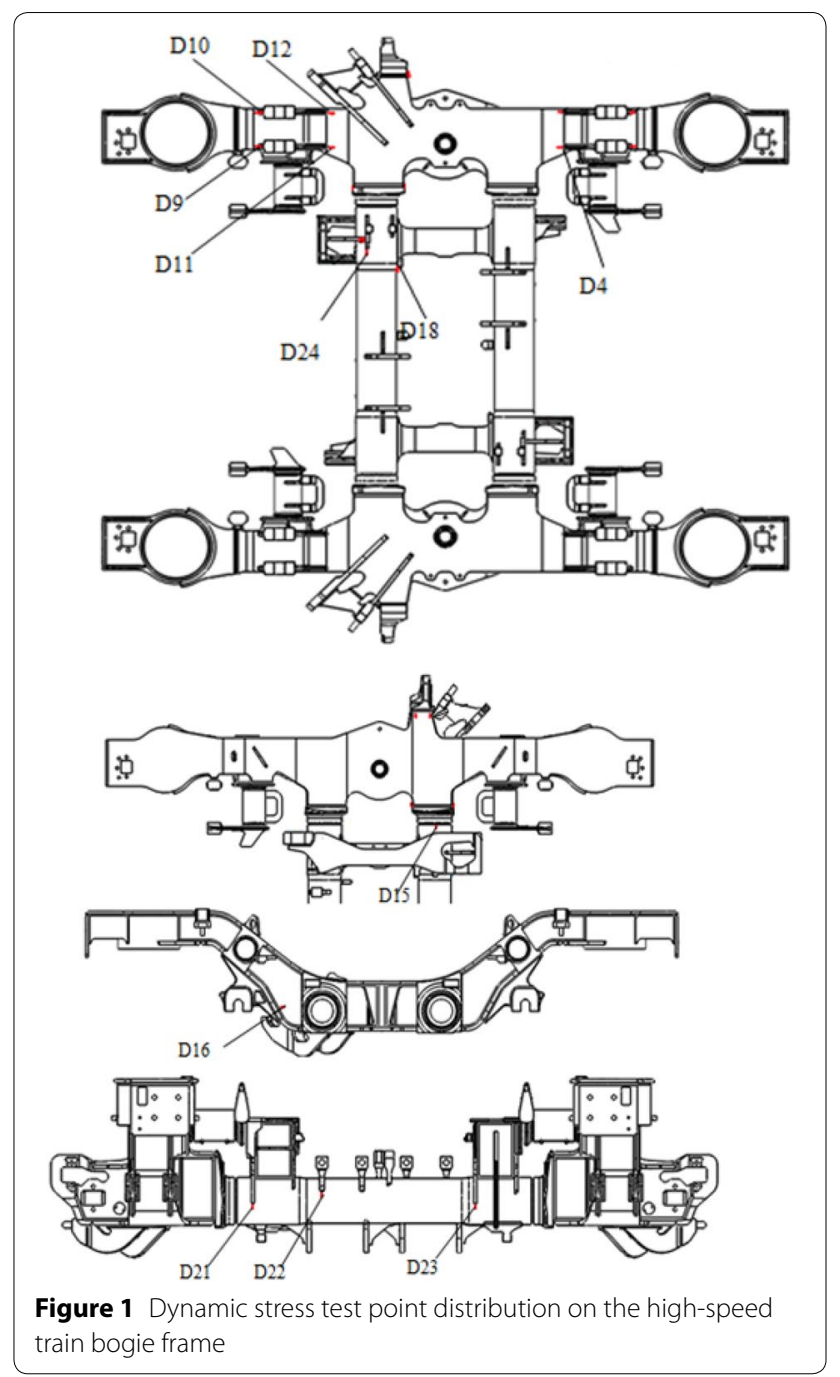

before calculating the fatigue damage under Miner damage accumulation theory based on the stress spectrum. The tested fatigue damage $D_{1}$, according to the tested miles $L_{1}$ $(\mathrm{km})$, is:

$$
D_{1}=\sum_{i=1}^{a} \frac{n_{i}}{N_{i}}+\sum_{j=1}^{b} \frac{n_{j}}{N_{j}}=\sum_{i=1}^{a} \frac{n_{i} \sigma_{i}^{m_{1}}}{C_{1}}+\sum_{j=1}^{b} \frac{n_{j} \sigma_{j}^{m_{2}}}{C_{2}},
$$

$\mathrm{S}-\mathrm{N}$ curve parameters can be determined based on Ref. [26].

The fatigue damage of equivalent stress $\sigma_{\mathrm{e}}$ after $2 \times 10^{6}$ cycles is denoted as $D$. The following equation makes $D$ equal to the total fatigue damage of the train according to the whole service life miles $L(\mathrm{~km})$ :

$$
D=\frac{N \sigma_{e}^{m_{1}}}{C_{1}} \text {. }
$$




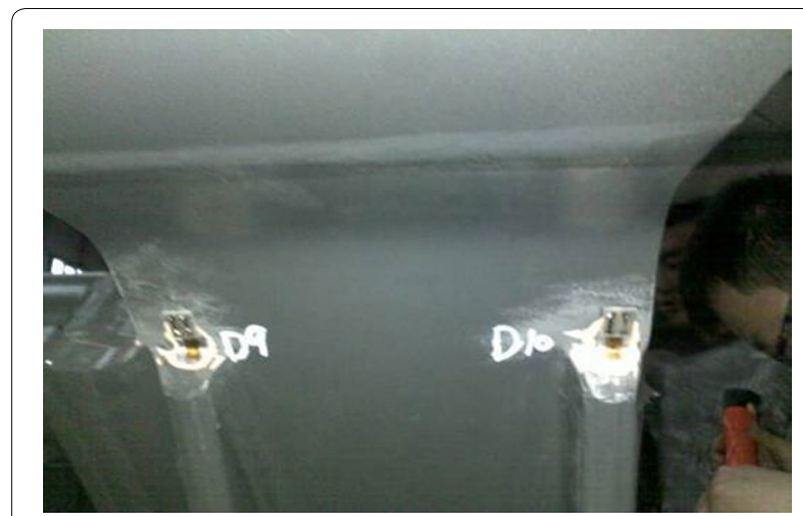

Figure 2 Strain gauge paste mode of the testing points

On the basis of the fatigue damage consistency law, tested damage $D_{1}$ should be equal to the entire damage $D$ per kilometer:

$$
\frac{D}{L}=\frac{D_{1}}{L_{1}} .
$$

Eq. (3) can be written as a stress-type equation:

$$
\frac{N \sigma_{e}^{m_{1}}}{C_{1} L}=\sum_{i=1}^{a} \frac{n_{i} \sigma_{i}^{m_{1}}}{C_{1} L_{1}}+\sum_{j=1}^{b} \frac{n_{j} \sigma_{j}^{m_{2}}}{C_{2} L_{1}},
$$

where

$$
\sigma_{e}=\left(\frac{L}{L_{1} N} \sum_{i=1}^{a} n_{i} \sigma_{i}^{m_{1}}+\frac{L C_{1}}{L_{1} C_{2} N} \sum_{j=1}^{b} n_{j} \sigma_{j}^{m_{2}}\right)^{1 / m_{1}} .
$$

Engineers often utilize the linear S-N curve to ensure structural safety [27]. Let $C_{2}=C_{1}, m_{2}=m_{1}$ so that Eq. (5) becomes:

$$
\sigma_{e}=\left(\frac{L}{L_{1} N} \sum_{k=1}^{a+b} n_{k} \sigma_{k}^{m_{1}}\right)^{1 / m_{1}} .
$$

Eq. (6) is the equivalent stress amplitude calculation formula based on the measured data. $L$ equals 12 million $\mathrm{km}$, according to the known high-speed train service life.

The dynamic stress responses of the bogie frame were obtained by the test program as the train ran on the Taiyuan-Guangzhou South line. The equivalent stress amplitudes according to Eq. (6) of each tested stress point are shown in Table 1.

A long-term tracking dynamic stress test was conducted on a passenger-carrying operation train with regular maintenance on common tracks, which represent the normal level. The equivalent stress amplitudes of D10 and D11
Table 1 Equivalent stress values of the frame under uniform operation (MPa)

\begin{tabular}{llll}
\hline Test points & \multicolumn{3}{l}{ Test data and service miles $\left.L_{\mathbf{1}} \mathbf{( k m}\right)$} \\
\cline { 2 - 4 } & $\mathbf{8 . 1 . 2 0 1 3}$ & $\mathbf{8 . 3 . 2 0 1 3}$ & $\mathbf{8 . 9 . 2 0 1 3}$ \\
& $\mathbf{2 6 2 , 6 4 4}$ & $\mathbf{2 6 7 , 6 7 9}$ & $\mathbf{2 7 7 , 9 7 9}$ \\
\hline D04 & 54.9 & 52.8 & 56.6 \\
D09 & 72.6 & 70.6 & 73.0 \\
D10 & 67.1 & 65.4 & 67.9 \\
D11 & 67.4 & 65.4 & 68.3 \\
D12 & 58.8 & 57.5 & 59.2 \\
D15 & 51.0 & 48.2 & 51.7 \\
D16 & 43.6 & 42.6 & 44.3 \\
D18 & 54.8 & 54.0 & 55.9 \\
D21 & 51.0 & 50.1 & 52.3 \\
D22 & 48.0 & 46.8 & 48.8 \\
D23 & 45.4 & 46.5 & 47.9 \\
D24 & 85.8 & 81.2 & 87.2 \\
\hline
\end{tabular}

Note: Due to the confidentiality requirements of the project, the equivalent stress amplitude data in the table is uniformly superimposed with an identical random number. Equivalent stress amplitude data presented below were processed in the same manner

along with the operating mileage from $18.5 \times 10^{4} \mathrm{~km}$ to $95.7 \times 10^{4} \mathrm{~km}$ are shown in Figures 3 and 4 .

\section{Methodology}

If the whole service miles of bogie frame is cut into $x$ pieces, the fatigue damage of each piece can be calculated as follows:

$$
D_{i=1,2 \ldots x}=\frac{\left(\sigma_{e}\right)_{i}^{m_{1}} N}{C_{1}} \frac{L_{i}}{L} .
$$

The whole fatigue damage of the bogie frame in total service miles is:

$$
D=\sum_{i=1}^{x} D_{i}=\sum_{i=1}^{x}\left[\frac{\left(\sigma_{e}\right)_{i}^{m_{1}} N}{C_{1}} \frac{L_{i}}{L}\right] .
$$

Because the ratio between test miles $L_{1}$ and whole service miles $L$ is the probability of each equivalent stress amplitude tested, Eq. (8) can be rewritten as follows:

$$
\begin{aligned}
D & =\sum_{i=1}^{x}\left[\frac{\left(\sigma_{e}\right)_{i}^{m_{1}} N}{C_{1}} \cdot p\left(\sigma_{e}\right)_{i}\right] \\
& =\frac{N}{C_{1}} \sum_{i=1}^{x}\left[\left(\sigma_{e}\right)_{i}^{m_{1}} p\left(\sigma_{e}\right)_{i}\right] .
\end{aligned}
$$

As the piece number $x$ increases towards infinity, Eq. (9) can be rewritten in integral form: 


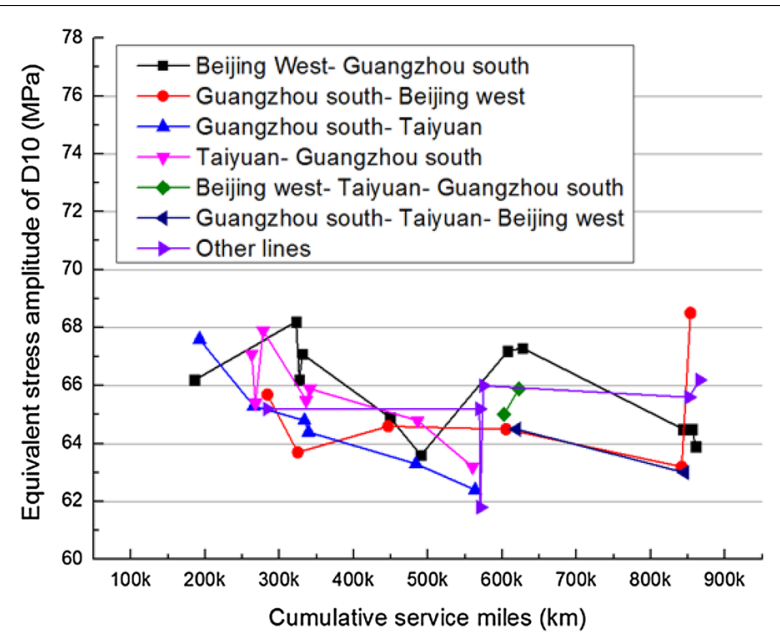

Figure 3 Equivalent stress amplitudes of D10 along with operating mileage

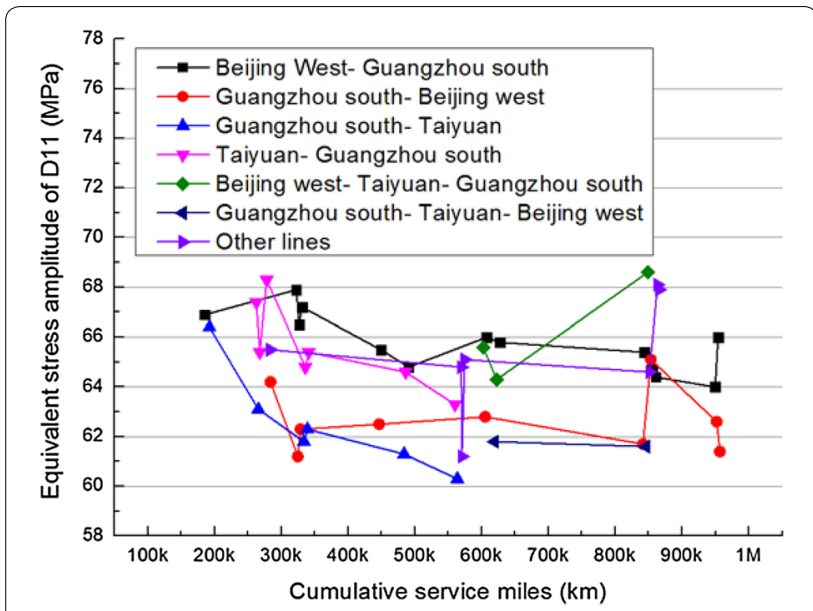

Figure 4 Equivalent stress amplitudes of D1 1 along with operating mileage

$$
\begin{aligned}
D & =\lim _{x \rightarrow \infty} \frac{N}{C_{1}} \sum_{i=1}^{x}\left[\left(\sigma_{e}\right)_{i}^{m_{1}} p\left(\sigma_{e}\right)_{i}\right] \\
& =\frac{N}{C_{1}} \int\left[\left(\sigma_{e}\right)_{i}^{m_{1}} p\left(\sigma_{e}\right)_{i}\right] \mathrm{d}\left(\sigma_{e}\right)_{i} .
\end{aligned}
$$

The following equation makes $\left[\sigma_{\mathrm{e}}\right]$ equal to the damage consistency equivalent stress amplitude according to the entire service mileage of the bogie frame:

$$
\left(\left[\sigma_{e}\right]\right)^{m_{1}}=\int\left[\left(\sigma_{e}\right)_{i}^{m_{1}} p\left(\sigma_{e}\right)_{i}\right] \mathrm{d}\left(\sigma_{e}\right)_{i}
$$

where the key to acquiring the damage consistency equivalent stress amplitude is in determining the probability distribution of tested equivalent stress amplitude.

\section{Application and Discussion}

By comparison between Figures 3 and 4, the equivalent stress amplitudes of D11 were selected to determine the probability distribution of tested equivalent stress amplitude on account of their randomness. Table 2 shows the tested equivalent stress amplitude values of D11 in different operation routes according to the information shown in Figure 4.

Due to the regular maintenance of railway lines and rail vehicles, the running performance of rail vehicles is relatively stable. It is reasonable to suppose that deviations among the tested equivalent stress amplitudes are caused by stochastic factors when running conditions are constant. The tested equivalent stress amplitudes can be written in the following form according to the error analysis theory:

$$
\sigma_{e}=\sigma+\varepsilon\left(0, s^{2}\right) .
$$

Predictably, the equivalent stress amplitude is in normal distribution $N\left(\sigma, s^{2}\right)$, so the whole service life fatigue damage of the bogie frame can be calculated as following formula under the " $3 \sigma$ Principle":

$$
D=\frac{N}{C_{1}} \int_{\sigma-3 s}^{\sigma+3 s}\left(\sigma_{e}\right)^{m_{1}} \cdot \frac{1}{\sqrt{2 \pi s}} e^{-\frac{\left(\sigma_{e}-\sigma\right)^{2}}{2 s^{2}}} \mathrm{~d}\left(\sigma_{e}\right) .
$$

Because the tested equivalent stress amplitude belongs to a small sample size, the Anderson-Darling test method was used to test whether the equivalent stress amplitude followed a normal distribution. The test statistic $\mathrm{AD}$ value can be determined as follows:

$$
A^{2}=-n-\frac{1}{n} \sum_{i=1}^{n}(2 i-1)\left(\ln F\left(X_{i}\right)+\ln \left(1-F\left(X_{n+1-i}\right)\right)\right) .
$$

Small $A$ value indicates that the tested equivalent stress amplitude obeys normal distribution. Normal distribution test conclusions are reflected by $P$-values, which can be acquired as follows:

$$
A^{\prime 2}=A^{2} \times\left(1+\frac{0.75}{n}+\frac{2.25}{n^{2}}\right) .
$$

When $13>A^{\prime 2}>0.600$,

$$
P=\exp \left(0.9177-4.279 \times A^{\prime 2}-1.38 \times\left(A^{\prime 2}\right)^{2}\right) .
$$

When $0.600>A^{\prime 2}>0.340$,

$$
P=\exp \left(0.9177-4.279 \times A^{\prime 2}-1.38 \times\left(A^{\prime 2}\right)^{2}\right) .
$$


Table 2 Tested equivalent stress values of D11 in different railway tracks (MPa)

\begin{tabular}{|c|c|c|c|c|c|}
\hline \multirow[t]{2}{*}{ No. } & \multicolumn{5}{|l|}{ Running railway lines } \\
\hline & $\begin{array}{l}\text { Beijing West-Guangzhou } \\
\text { South }\end{array}$ & $\begin{array}{l}\text { Guangzhou South- } \\
\text { Beijing west }\end{array}$ & $\begin{array}{l}\text { Guangzhou South- } \\
\text { Taiyuan }\end{array}$ & $\begin{array}{l}\text { Taiyuan-Guangzhou } \\
\text { South }\end{array}$ & $\begin{array}{l}\text { Beijing West- } \\
\text { Taiyuan- } \\
\text { Guangzhou South }\end{array}$ \\
\hline 1 & 66.9 & 64.2 & 66.4 & 67.4 & 65.6 \\
\hline 2 & 67.9 & 61.2 & 63.1 & 65.4 & 64.3 \\
\hline 3 & 66.5 & 62.3 & 61.8 & 68.3 & 68.6 \\
\hline 4 & 67.2 & 62.5 & 62.3 & 64.8 & \\
\hline 5 & 65.5 & 62.8 & 61.3 & 65.4 & \\
\hline 6 & 64.8 & 61.7 & 60.3 & 64.6 & \\
\hline 7 & 66.0 & 65.1 & & 63.3 & \\
\hline 8 & 65.8 & 62.6 & & & \\
\hline 9 & 65.4 & 61.4 & & & \\
\hline 10 & 64.7 & & & & \\
\hline 11 & 64.4 & & & & \\
\hline 12 & 64.0 & & & & \\
\hline 13 & 66.0 & & & & \\
\hline
\end{tabular}

Table 3 Normal test result of D11 testing point by Anderson-Darling test method

\begin{tabular}{llllll}
\hline Item & \multicolumn{2}{l}{ Running railway lines } & & & \\
\cline { 2 - 6 } & $\begin{array}{l}\text { Beijing West- } \\
\text { Guangzhou South }\end{array}$ & $\begin{array}{l}\text { Guangzhou South- } \\
\text { Beijing West }\end{array}$ & $\begin{array}{l}\text { Guangzhou South- } \\
\text { Taiyuan }\end{array}$ & $\begin{array}{l}\text { Taiyuan-Guangzhou } \\
\text { South }\end{array}$ & $\begin{array}{l}\text { Beijing West- } \\
\text { Taiyuan- } \\
\text { Guangzhou South }\end{array}$ \\
\hline Sample size & 13 & 9 & 6 & 7 & 3 \\
AD value & 0.14 & 0.40 & 0.38 & 0.32 & 0.25 \\
Mean value & 65.78 & 62.64 & 62.53 & 65.60 & 66.17 \\
Standard deviation & 1.15 & 1.28 & 2.12 & 1.71 & 2.21 \\
P value & 0.96 & 0.28 & 0.28 & 0.42 & 0.43 \\
\hline
\end{tabular}

When $0.340>A^{\prime 2}>0.200$,

$$
P=\exp \left(-8.318+42.796 \times A^{\prime 2}-59.938 \times\left(A^{\prime 2}\right)^{2}\right)
$$

When $A^{\prime 2}<0.200$,

$$
P=\exp \left(-13.436+101.14 \times A^{\prime 2}-223.73 \times\left(A^{\prime 2}\right)^{2}\right) .
$$

When the confidence coefficient is 95\%, the assumption that tested equivalent stress amplitude closely obeys a normal distribution should be rejected if $P<0.05$. The data shown in Table 2 was tested by Anderson-Darling test method to obtain the results shown in Table 3; said data does indeed follow normal distribution.

Table 4 shows the damage consistency equivalent stress amplitude of each railway line, which corresponds to fatigue damage, calculated by the method introduced in
Table 4 Damage consistency equivalent stress amplitude of each railway line (MPa)

\begin{tabular}{lllll}
\hline $\begin{array}{l}\text { Beijing } \\
\text { West- } \\
\begin{array}{l}\text { Guangzhou } \\
\text { South }\end{array}\end{array}$ & $\begin{array}{l}\text { Guangzhou } \\
\text { South- } \\
\text { Beijing } \\
\text { West }\end{array}$ & $\begin{array}{l}\text { Guangzhou } \\
\text { South- } \\
\text { Taiyuan }\end{array}$ & $\begin{array}{l}\text { Taiyuan- } \\
\text { Guangzhou } \\
\text { South }\end{array}$ & $\begin{array}{l}\text { Beijing } \\
\text { West- } \\
\text { Taiyuan- } \\
\text { Guangzhou } \\
\text { South }\end{array}$ \\
\hline 65.74 & 62.61 & 62.54 & 65.58 & 66.18 \\
\hline
\end{tabular}

Section 3. Different railway lines exhibited different fatigue damage values, even on twin lines (e.g., Beijing WestGuangzhou South versus Guangzhou South-Beijing West). To compute the fatigue damage of the bogie frame as accurately as possible over the entire service life, both the damage consistency equivalent stress amplitude of each railway line train running and the operation schedule of the train are needed. These values allow the whole service life fatigue damage of the bogie frame to be calculated as follows: 


$$
D=\frac{N}{C_{1}} \sum_{i=1}^{a}\left[\sigma_{e}\right]_{i}^{m_{1}} p_{i}
$$

The complex load conditions of the bogie frame create different stress responses across different locations on the frame, so the mean value are also disparate. The difference between the standard deviations merit further research. The data in Table 1 was transformed into a new sample group to analyze the distributed standard deviation parameters as follows:

$$
\left(\sigma_{e}^{\prime}\right)_{i j}=\left(\sigma_{e}\right)_{i j}-\frac{1}{j} \sum_{j=1}^{n}\left(\sigma_{e}\right)_{i j}
$$

The standard deviation parameters of the testing points are relatively uniform if the new sample group can be represented by a normal distribution. The Anderson-Darling normality test results are shown in Table 5, where the new sample can be considered to have a significant normal distribution. The estimated distribution parameters of each bogie frame testing point are shown in Table 6, where no standard deviations exceed 3 except the D24 testing point, which is slightly greater than 3; point D24 is located in the connection region of the frame and power device gear-box.

Based on the above analysis, the equivalent stress amplitude of the frame can be represented by a normal distribution within 12 million $\mathrm{km}$ and the standard deviation is generally 3 or less. To make the integral part of Eq. (13) equal $G, G$ is expressed as follows:

$$
G=\int_{\sigma-3 s}^{\sigma+3 s}\left(\sigma_{e}\right)^{m_{1}} \cdot \frac{1}{\sqrt{2 \pi} s} e^{-\frac{\left(\sigma_{e}-\sigma\right)^{2}}{2 s^{2}}} \mathrm{~d}\left(\sigma_{e}\right) .
$$

$G$ value reflects the fatigue damage of the bogie frame. Its value was consistently calculated to be under the mean value $10-90 \mathrm{MPa}$, with standard deviation of $0.5-3$ (Figure 5). Its projection along standard deviation direction is shown in Figure 6, where the width of the data line represents the impact of standard deviation to the $G$ value.

The small range of the standard deviation indicates that fatigue damage is mainly affected by the mean value. Therefore, an accurate mean value estimate of equivalent stress amplitude distribution is an essential component of the on-track dynamic stress fatigue test program.

Table 5 Normal test result of new sample group by Anderson-Darling method

\begin{tabular}{lllll}
\hline Sample size & AD value & Mean value & Standard deviation & P value \\
\hline 36 & 0.57 & $5.67 \times 10^{-16}$ & 1.28 & 0.13 \\
\hline
\end{tabular}

Table 6 Estimated distribution parameters of each bogie frame testing point

\begin{tabular}{lll}
\hline Test point & Mean value & $\begin{array}{l}\text { Standard } \\
\text { deviation }\end{array}$ \\
\hline D04 & 54.77 & 1.90 \\
D09 & 72.07 & 1.29 \\
D10 & 66.80 & 1.28 \\
D11 & 67.03 & 1.48 \\
D12 & 58.50 & 0.89 \\
D15 & 50.30 & 1.85 \\
D16 & 43.50 & 0.85 \\
D18 & 54.90 & 0.95 \\
D21 & 51.13 & 1.11 \\
D22 & 47.87 & 1.01 \\
D23 & 46.60 & 1.25 \\
D24 & 84.73 & 3.14 \\
\hline
\end{tabular}
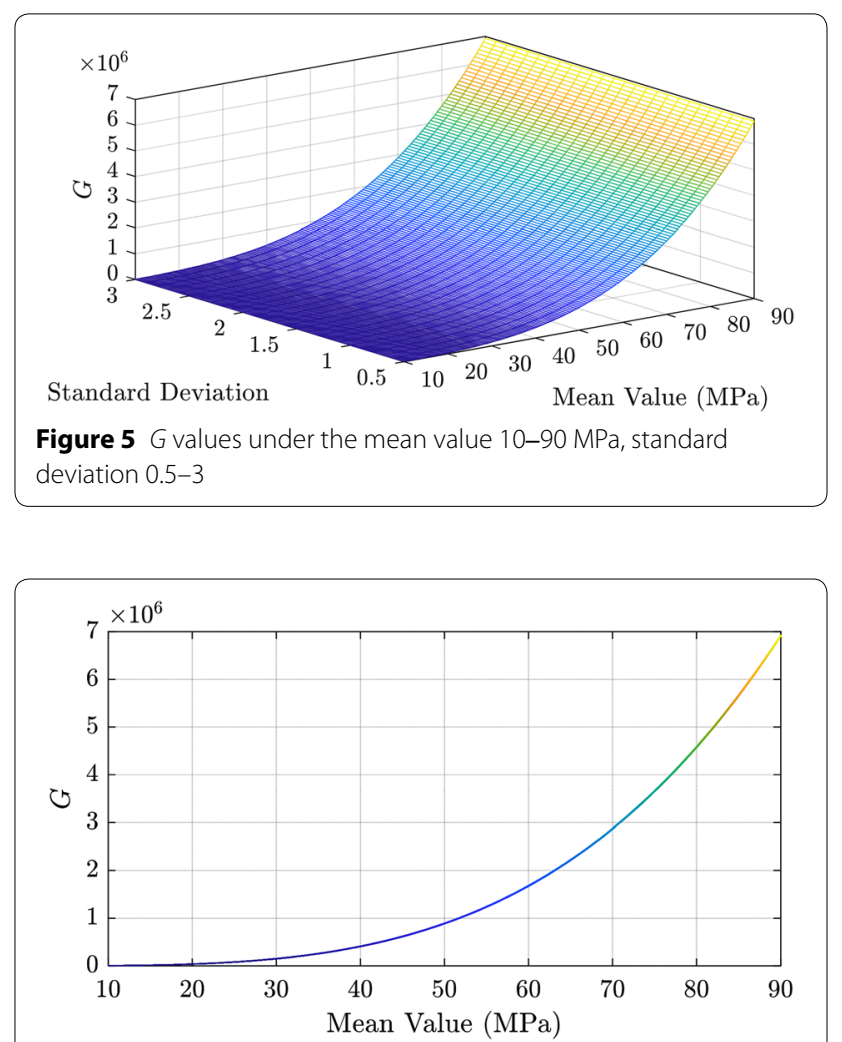

Figure $6 \mathrm{G}$ value projection along standard deviation direction

\section{Conclusions}

Studies have shown that high-speed train bogie frame fatigue damage contains randomness though in the same operation route. The evaluation method proposed in this paper can be adapted to accurately assess the fatigue damage of the bogie frame. Several characteristics of the 
fatigue damage to the bogie frame were identified here by analyzing actual dynamic stress testing data.

(1) The equivalent stress amplitude on behalf of the bogie frame fatigue damage can be obtained by integral based on normal distribution and $3 \sigma$ Principle, especially when conditions are constant. The mean value of distribution parameters is dependent on the specific location of the test point; the standard deviation maximum value is about 3. Standard deviation does not significantly affect fatigue damage, but mean value has a great effect on it, so the mean value evaluation accuracy should be the primary focus in establishing the test program.

(2) Bogie frame fatigue damage differs when the train runs on different operation routes, even across twin lines. When the damage consistency equivalent stress amplitude of each running railway line and the operation schedule of the train are known a priori, the whole service life fatigue damage of the bogie frame can be calculated precisely. Fatigue damage varies across specific locations on the frame, but the dynamic stress responses of the region connected to the power system are generally more random than the responses in other regions.

\section{Authors' Contributions}

GY wrote the manuscript; QL was in charge of the whole trial; MW assisted with data analyses; RD assisted with the theoretical analysis. All authors read and approved the final manuscript.

\section{Author Details}

${ }^{1}$ Engineering Research Center of Structure Reliability and Operation Measurement Technology of Rail Guided Vehicles, Ministry of Education, Beijing Jiaotong University, Beijing 100044, China. ${ }^{2}$ Standards \& Metrology Research Institute, China Academy of Railway Sciences, Beijing 100081, China.

\section{Authors' Information \\ Guangxue Yang, born in 1982, is currently a associate professor at Beijing Jiaotong University, China. He received his PhD degree from Beijing Jiaotong University in 2011. His research interests include structural strength, reliability and load spectra. \\ Meng Wang, born in 1987, is currently an engineer at China Academy of Railway Sciences, China. He received his PhD degree from Beijing Jiaotong University in 2016. \\ Qiang Li, born in 1963, is currently a professor at Beijing Jiaotong Univer- sity, China. He received his PhD degree from Beijing Jiaotong University in 1995. \\ Ran Ding, born in 1989, is currently a PhD candidate at Beijing Jiaotong University, China.}

\section{Competing Interests}

The authors declare that they have no competing interests.

\section{Funding}

Supported by National Key Research and Development Program of China (Grant No. 2018YFB1201704) and National Natural Science Foundation of China (Major Program, Grant No. 11790281).
Received: 20 July 2018 Accepted: 22 May 2019

Published online: 04 June 2019

\section{References}

[1] M Kassner. Fatigue strength analysis of a welded railway vehicle structure by different methods. International Journal of Fatigue, 2012, 34(1): 103-111.

[2] S Dietz, H Netter, D Sachau. Fatigue life prediction of a railway bogie under dynamic loads through simulation. Vehicle System Dynamics, 1998, 29: 385-402.

[3] V J Lucanin, G Z Simic, D C Milkovic, et al. Calculated and experimental analysis of cause of the appearance of cracks in the running bogie frame of diesel multiple units of Serbian railways. Engineering Failure Analysis, 2010, 17(1): 236-248.

[4] JW Han, J D Kim, S Y Song. Fatigue strength of a bogie frame for urban maglev train with fatigue test on full-scale test rig. Engineering Failure Analysis, 2013, 31: 412-420.

[5] R C A Liliana, B Florin, I Nicolae, et al. Stresses in a bogie frame of a rail carriage. Procedia Engineering, 2015, 100: 482-487.

[6] Motive power units-Bogies and running gear-Bogie frame structure strength tests. International Union of Railways UIC Code615-4, 2003.

[7] JW Han, J D Kim, SY Song. Fatigue strength evaluation of a bogie frame for urban maglev train with fatigue test on full-scale test rig. Engineering Failure Analysis, 2013, 31: 412-420.

[8] V Linhart, I Černý. An effect of strength of railway axle steels on fatigue resistance under press fit. Engineering Fracture Mechanics, 2011, 78: 731-741.

[9] SCWu, S Q Zhang, ZW Xu, et al. Cyclic plastic strain based damage tolerance for railway axles in China. International Journal of Fatigue, 2016, 93(1): 64-70.

[10] L Bertini, A Cera, F Frendo, et al. Experimental investigation of the fatigue resistance of pipe-to-plate welded connections under bending, torsion and mixed mode loading. International Journal of Fatigue, 2014, 68: $178-185$.

[11] SX Zhou, F S Li, J L Xie, et al. Equivalent stress evaluation of the load spectrum measured on the EMU axle based on damage tolerance. Journal of Mechanical Engineering, 2015, 51(8): 131-136. (in Chinese)

[12] V Milovanović, V Dunić, D Rakić, et al. Identification causes of cracking on the underframe of wagon for containers transportation-Fatigue strength assessment of wagon welded joints. Engineering Failure Analysis, 2013, 31 : $118-131$.

[13] S Cervello. Fatigue properties of railway axles: New results of full-scale specimens from Euraxles project. International Journal of Fatigue, 2016, 86: 2-12.

[14] D L Fu, W J Wang, L Dong. Analysis on the fatigue cracks in the bogie frame. Engineering Failure Analysis, 2015, 58: 307-319.

[15] Z S Ren, S G Sun, Q Li. Axle spring load test and dynamic characteristics analysis of high speed EMU. Journal of Mechanical Engineering, 2010, 46(10): 109-115. (in Chinese)

[16] N Zhu, S G Sun, Q Li, et al. Theoretical research and experimental validation of quasi-static load spectra on bogie frame structures of high-speed trains. Acta Mechanica Sinica, 2014, 30(6): 901-909.

[17] XW Wu, M R Cji, H Gao. The study of post-derailment dynamic behavio of railway vehicle based on running tests. Engineering Failure Analysis, 2014, 44: 382-399.

[18] P Wolfsteiner, W Breuer. Fatigue assessment of vibrating rail vehicle bogie components under non-Gaussian random excitations using power spectral densities. Journal of Sound and Vibration, 2013, 332(22): 5867-5882.

[19] M Hong, Q Wang, Z Q Su, et al. In situ health monitoring for bogie systems of $\mathrm{CRH} 380$ train on Beijing-Shanghai high-speed railway. Mechanical Systems and Signal Processing, 2014, 45(2): 378-395.

[20] B S Chen, Y X Zhao, B Yang. Scale-induced effects on fatigue properties of a cast steel for bogie frames of China railway rolling wagons. International Journal of Fatigue, 2012, 35(1): 45-55.

[21] J Chvojana, JVaclavika. Experimental methods for the GRP bogie structure integrity assessment. Procedia Engineering, 2015, 114:627-634.

[22] C M Lee, V N Goverdovskiy, C S Sim, et al. Ride comfort of a high-speed train through the structural upgrade of a bogie suspension. Journal of Sound and Vibration, 2016, 361(20): 99-107. 
[23] A Esderts, J Willen, M Kassner. Fatigue strength analysis of welded joints in closed steel sections in rail vehicles. International Journal of Fatigue, 2012, 34(1): 112-121.

[24] G Gou, M Zhang, H Chen, et al. Effect of humidity on porosity, microstructure, and fatigue strength of A7N01S-T5 aluminum alloy welded joints in high-speed trains. Materials and Design, 2015, 85: 309-317.

[25] G J Xue, K Li, W Pan, et al. Estimation of dynamic stress spectrum distribution in structural fatigue test. Theoretical and Applied Mechanics Letters 2013, 3(2): 021010, 1-6.
[26] UK National Annex to Eurocode3: Design of steel structures - Part 1-9: Fatique. BS EN 1993-1-9, 2005.

[27] Standard Specifications for Highway Bridges. Washington DC: American Association of State Highway and Transportation Officials, 2002.

\section{Submit your manuscript to a SpringerOpen ${ }^{\circ}$ journal and benefit from:}

- Convenient online submission

- Rigorous peer review

- Open access: articles freely available online

- High visibility within the field

- Retaining the copyright to your article

Submit your next manuscript at $\boldsymbol{\nabla}$ springeropen.com 